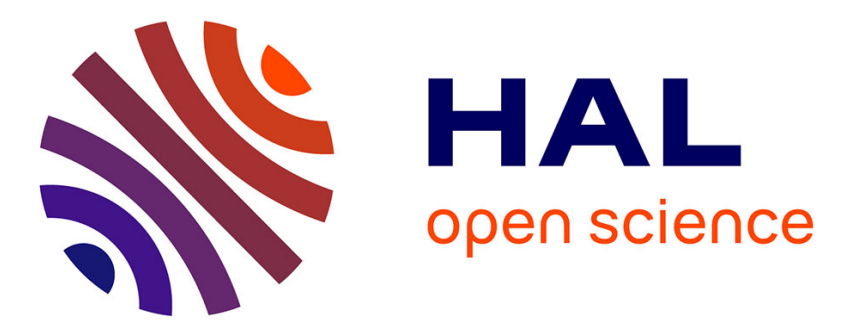

\title{
Mass transfer characteristics and concentration field evolution for gas-liquid Taylor flow in milli channels
}

R.Sh. Abiev, Colin Butler, Emmanuel Cid, Benjamin Lalanne, Anne-Marie

Billet

\section{- To cite this version:}

R.Sh. Abiev, Colin Butler, Emmanuel Cid, Benjamin Lalanne, Anne-Marie Billet. Mass transfer characteristics and concentration field evolution for gas-liquid Taylor flow in milli channels. Chemical Engineering Science, 2019, 207, pp.1331-1340. 10.1016/j.ces.2019.07.046 . hal-02270667

\section{HAL Id: hal-02270667 \\ https://hal.science/hal-02270667}

Submitted on 26 Aug 2019

HAL is a multi-disciplinary open access archive for the deposit and dissemination of scientific research documents, whether they are published or not. The documents may come from teaching and research institutions in France or abroad, or from public or private research centers.
L'archive ouverte pluridisciplinaire HAL, est destinée au dépôt et à la diffusion de documents scientifiques de niveau recherche, publiés ou non, émanant des établissements d'enseignement et de recherche français ou étrangers, des laboratoires publics ou privés. 


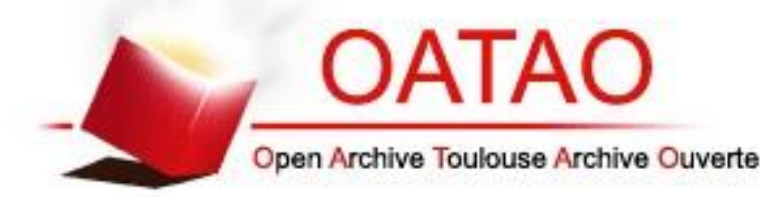

\section{Open Archive Toulouse Archive Ouverte}

OATAO is an open access repository that collects the work of Toulouse researchers and makes it freely available over the web where possible

This is an author's version published in: http://oatao.univ-toulouse.fr/24193

Official URL: https://doi.org/10.1016/j.ces.2019.07.046

\section{To cite this version:}

Abiev, R.Sh. and Butler, Colin 5 and Cid, Emmanuel $\leftrightarrows$ and Lalanne, Benjamin $\leftrightarrows$ and Billet, Anne-Marie $\leftrightarrows$ Mass transfer characteristics and concentration field evolution for gas-liquid Taylor flow in milli channels. (2019) Chemical Engineering Science, 207. 1331-1340. ISSN 0009-2509

Any correspondence concerning this service should be sent to the repository administrator: tech-oatao@listes-diff.inp-toulouse.fr 


\title{
Mass transfer characteristics and concentration field evolution for gas-liquid Taylor flow in milli channels
}

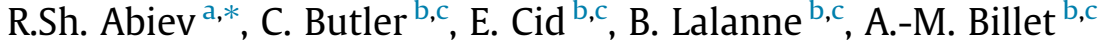 \\ ${ }^{a}$ St. Petersburg State Institute of Technology (Technical University), Department of Optimization of Chemical and Biotechnological Equipment, \\ 26 Moskovskii pr., 190013 Saint Petersburg, Russia \\ ${ }^{\mathrm{b}}$ Laboratoire de Génie Chimique, Université de Toulouse, CNRS, INPT, UPS, Toulouse, France \\ ${ }^{\mathrm{c}}$ FERMAT, Université de Toulouse, CNRS, INP, INSA, UPS, Toulouse, France
}

\section{H I G H L I G H T S}

- Mass transfer of gas-liquid Taylor flow in milli channels is analysed.

- Small scale convection by Taylor vortices in the liquid slugs plays a key role.

- Periodical nature of liquid mass transfer is directly linked to global transfer rate.

- $\mathrm{k}_{\mathrm{L}} \mathrm{a}$ is proportional to circulation frequency in liquid slugs in most conditions.

- Influence of flow behavior at T-mixer on the concentration patterns is discussed
G R A P H I C A L A B S T R A C T
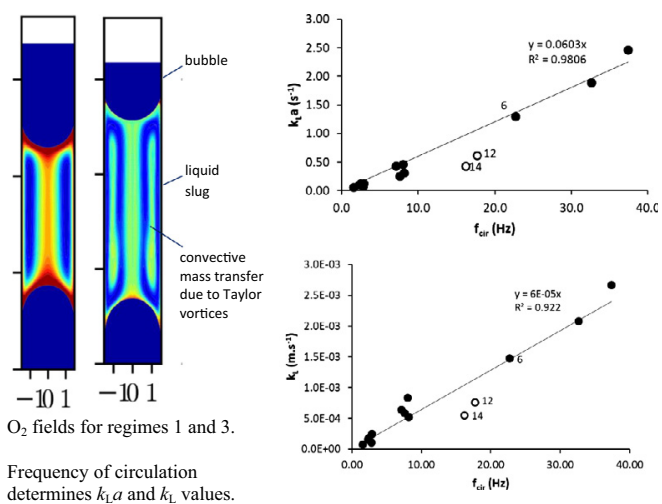

The results of the recent experimental work performed by Butler et al. $(2016,2018)$ are analysed based on the dominant phenomena: (i) small scale convection by means of Taylor vortices in the liquid slugs and (ii) diffusion in lubrication film. A main result shown here is that the Taylor circulation frequency is able to reflect the global mass transfer rate in gas-liquid Taylor flow through an almost linear relationship, which emphasizes the interest of the circulating motion in the slug, and gives a very simple correlation to predict the $k_{\mathrm{L}} a$ value (at large Schmidt number). A mechanism of flow behavior during the bubble formation at the T-mixer is proposed as a possible explanation of unexpected concentration areas (called "islands"). However, despite of these unusual concentration field structures in these cases, the mass transfer rate coefficient $k_{\mathrm{L}} a$ is still accurately predicted by the Taylor circulation frequency in the slug.

\section{Introduction}

Over past decades micro and milli apparatuses, including both single channel and multichannel catalytic reactors, have attracted interest from researchers and industry due to their excellent heat

\footnotetext{
* Corresponding author.

E-mail address: abiev.rufat@gmail.com (R.Sh. Abiev).
}

and mass transfer characteristics. For example, it was found that the mass transfer coefficient is 3-5 times greater in two-phase Taylor flow (also called slug flow) when compared to stirred bubble vessels or columns. Hereinafter we will consider the hydrodynamics and mass transfer at milli level.

The investigation of overall mass transfer in gas liquid Taylor flow has benefitted from many previous contributions, starting from the paper of Bercic and Pintar (1997), where the $k_{\mathrm{L}} a$ was 


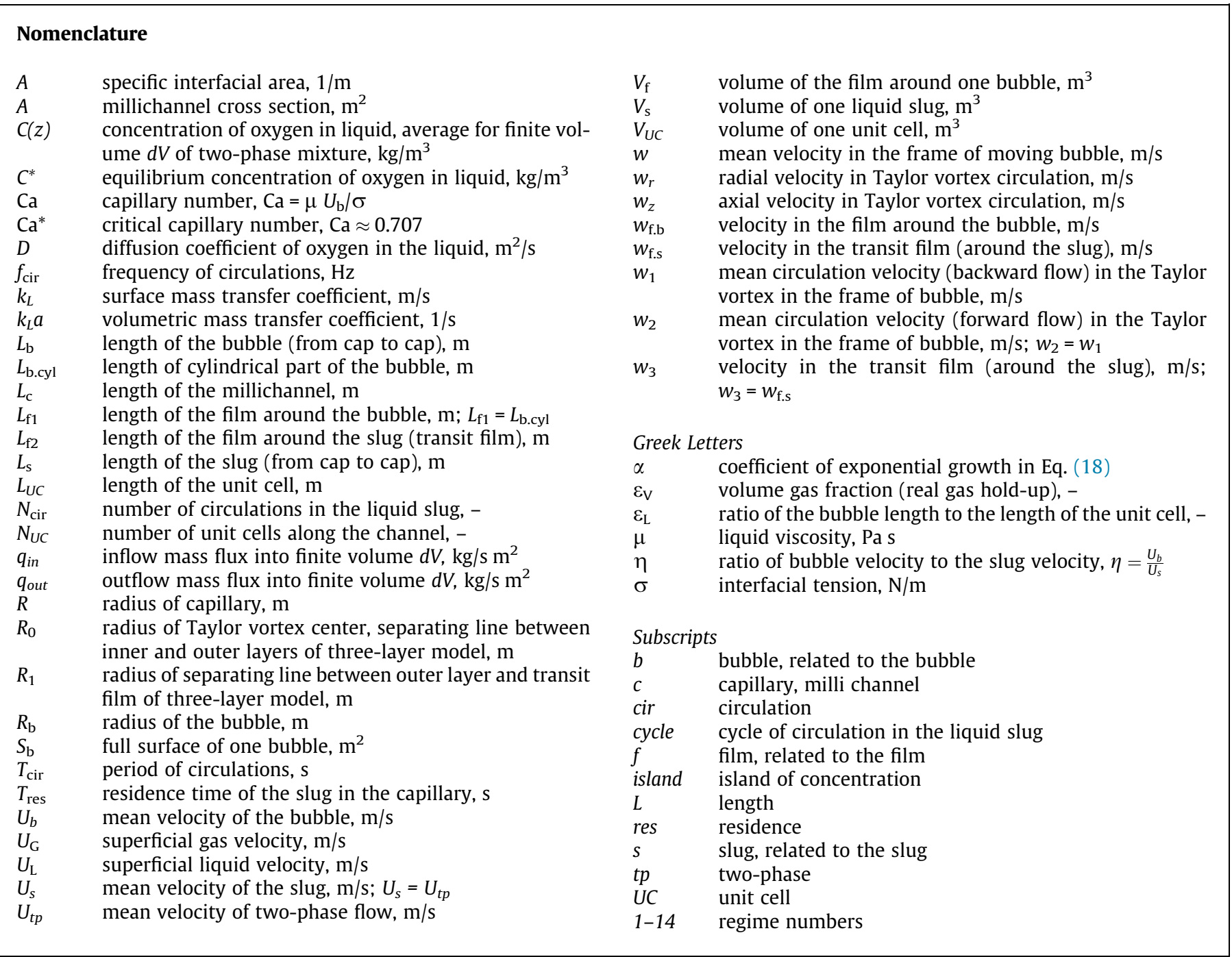

scaled as a function of gas hold-up, unit cell length and velocity. An extended review of mass transfer models performed in Sattari-Najafabadi et al. (2018) includes a list with over a dozen correlations of mass transfer coefficients in gas-liquid flow in microchannels. Some provide the relationship in the form $\mathrm{Sh}=\mathrm{f}$ $\left(\operatorname{Re}_{\mathrm{G}}, \mathrm{Re}_{\mathrm{L}}, \mathrm{Sc}_{\mathrm{L}}, \mathrm{Ca}\right)$, while others (Yue et al., 2009) take into account relative length of the bubbles.

However, these equations give only general information about mass exchange without explanation of the transferred gas concentration evolution in the liquid phase. The understanding of this evolution is necessary for process parameter optimisation and is a solid base for appropriate (physically based) equation building. This is why other works have focused on small-scale phenomena in these flows in an effort to scale mass transfer rate to local mechanisms. Kreutzer et al. (2001) have presented an overall mass transfer rate as a sum of two parallel processes: (i) directly from gas bubble to the solid wall and (ii) from gas bubble to the solid wall through the slug. A local experimental investigation of local mass transfer between bubbles, slugs and lubrication films was performed in Taylor flows with systems of air and aqueous solutions in a $3 \mathrm{~mm}$ glass channel (Butler et al., 2016, 2018). In this work, two experimental optical techniques were used to present high-resolution time-averaged measurements of the dissolved gas concentration in the liquid slugs. The shadowgraphy method gives information on the bubble and slug size, shape and velocity, as well as lubrication film thickness. The PLIF-I technique (Planar
Laser-Induced Fluorescence - Inhibited by oxygen), was used to capture the concentration fields of dissolved gas in not only the liquid slugs, but also the thin lubrication films between the bubble and channel walls. From these measurements it was possible to determine the separate contributions of the spherical bubble caps and the lubrication films to the overall volumetric mass transfer coefficient $k_{L} a$. Their experimental results showed that currently existing models in the literature (such as van Baten and Krishna, 2004) fail to accurately predict the $k_{L} a$ values for cases of short slug length (less than two times the channel diameter). The highresolution results obtained in Butler et al. (2018) have also disclosed some unusual effects of concentration distribution in the liquid slug, e.g. some isolated areas with increased oxygen concentration. The impact of the slugs' length on the concentration fields was also observed but still not fully explained.

Yang et al. (2017) have used the colorimetric technique proposed by Dietrich et al. (2013) for the analysis of mass transfer around Taylor bubbles in a meandering square milli-channel. The influence of the "turning point" joining two "straight" sections of meandering channel on the evolution of the concentration fields was described. Kováts et al. (2018) have experimentally studied gas-liquid mass transfer of oxygen in a helically-coiled pipe and presented a locally resolved description of gas-liquid mass transfer in this device using an optical colorimetric method. Methylene blue and Resazurin tracers were used during redox reactions. Using the experimental images, the dimensions of the bubbles and 
gas-liquid cell were determined. When comparing their device to a horizontal tube of the same diameter, the mass transfer is significantly increased in the helix, due to improved radial mixing and different flow patterns. In some cases, the oxygen concentration was two times greater in the helix compared to the horizontal tube.

The role of liquid film in liquid-liquid flows in capillaries which are in general similar to gas-liquid Taylor flows - was also studied. In Matsuoka et al. (2016), the effect of the droplet length on mass transfer was investigated in a circular channel with a $1 \mathrm{~mm}$ inner diameter connected to T-mixers with inner diameters of $2.0 \mathrm{~mm}$ and $2.4 \mathrm{~mm}$. Although the droplets lengths were varied in the range of 7.4-30.5 $\mathrm{mm}$, approximately the same volumetric mass transfer coefficients were obtained. This result was explained in (Matsuoka et al., 2016) as follows: the side interface area increases with increasing droplet length and droplet volume while the specific interfacial area remains approximately constant. One of the recent reviews of Wang and Luo (2017) includes information about mass transfer at the droplet generation stage and the later flowing stage.

Sattari-Najafabadi and Nasr Esfahany (2017) have examined how hydrodynamics and mass transfer are influenced by the presence of surfactant (sodium dodecyl sulfate SDS) in liquid-liquid Taylor flow. They used a PTFE microchannel with an internal diameter of $0.6 \mathrm{~mm}$. The applied methodology for estimating mass transfer coefficients increased the accuracy of previous results considerably. It was found that the SDS presence in the aqueous phase caused a decrease in slug length of both phases due to its negative impact on interfacial tension. However, improved recirculation inside the slugs were the main cause for the enhanced mass transfer. The influence of SDS was found to have greater impact on internal circulations rather than on the interfacial area. Although an increase in mass transfer coefficients were observed with the SDS concentration, the benefits were less noticeable at higher concentrations.

Concerning modelling of the transfer in Taylor flows, among recent theoretical works, the three-layer mass transfer model for slug flow in both milli- and micro channels proposed in Abiev (2013) was used in Svetlov and Abiev (2016) to study liquidsolid mass transfer in gas-liquid Taylor flow. This model appears to be a promising and relatively easy tool to understand the inner details of this process from an informal physical point of view, and gives prospects that can be applied to gas-liquid Taylor flows. The three-layer mass transfer model gives some general ideas to be applied for each special case, depending on which parts and stages of mass transfer predominate.

The general aim of this work is then to find new tools for mathematical description of mass transfer in two-phase Taylor flow, and to bring to light characteristics of dissolved gas concentration field and of its evolution. In other words, this work is an interpretation, systematisation and understanding of the experimental results concerning the gas-liquid mass transfer process in two-phase flow in milli channels, on the basis of the high-resolved data recently published by Butler et al. (2016, 2018), through a theoretical approach and by use of three-layer approach for Taylor flow (Abiev, 2013). This approach is applied for qualitative characterisation of mass transfer in two-phase gas-liquid Taylor flow as a function of circulation frequency.

\section{Experimental background of this work}

Experimental results of previous research by some authors of this paper have been used in this work (Butler et al., 2016, 2018), where a detailed description of the experimental rig, materials and methods can be found.
The experimental setup is summarised below.

\subsection{Experimental facility used in Butler et al. (2016, 2018)}

The channel in which the flow is generated consists of a single glass tube with a circular internal diameter of $3 \mathrm{~mm} \pm 0.01 \mathrm{~mm}$. The liquid phase is circulated through the channel in a closed loop by use of a reservoir tank, and a gear pump. The flow rate is regulated by a mass flow controller. The gas phase is supplied by a pressurised cylinder with controlled flow rate and generates the Taylor bubbles at a T-mixer located at the inlet of the tube. This injection system can be setup in such a fashion allowing either concurrent ascending or descending flows to be generated. The gas and liquid phases then travel along the tube in the form of Taylor flow. Nitrogen was also used to deoxygenate the liquid before it enters the channel through a submerged sparging system present in the reservoir.

Nitrogen was also used during a calibration procedure in order to determine the gas concentration levels present in the liquid. This is an important step for the PLIF-I measurement technique described later. Pure nitrogen or oxygen, and three different known mixtures of these two gases, allows for the determination of the dissolved oxygen concentration through the measured fluorescence intensity seen by the camera and the Stern-Volmer relationship.

\subsubsection{Imaging and laser systems}

To identify the characteristic parameters of the flow - bubble size, shape and velocity, as well as plug size and lubrication film thickness - shadowgraphy measurements were performed with high spatial resolution $(\sim 7 \mu \mathrm{m} /$ pixel for description in radial direction). A Phlox LED panel illuminates the tube by continuous backlighting. The field of view is $18 \times 3.8 \mathrm{~mm}$ allowing to image the complete unit cells. The frequency of acquisition was $100 \mathrm{~Hz}$ for shadowgraphy measurements.

To locally characterise mass transfer by PLIF-I, a tracer (Dichlorotris (1,10-phenanthroline) ruthenium (II) hydrate) is dissolved in the liquid phase (water) with a concentration of $50 \mathrm{mg} / \mathrm{L}$. The fluorescence of this tracer is inhibited in the presence of dissolved oxygen. This Ruthenium complex is excited by a laser at $460 \mathrm{~nm}$ with a frequency of $20 \mathrm{~Hz}$ : a thin laser sheet illuminates the diametral plane of the tube. The fluorescence signal is captured by the same camera and optics as those used for shadowgraphy acquisitions. An optical high-pass filter allows to separate the fluorescence signal from incident laser light.

\subsubsection{Experimental procedure}

The evolution of the dissolved oxygen concentration values are quantified at four different positions along the tube length. Two of these values come from analysis of the acquired PLIF-I and shadowgraphy images, while the two others are measured by the oxygen sensor at the channel inlet and outlets.

For the PLIF-I measurements, the camera and laser systems were setup at a distance $z$ from the T-mixer inlet. For this stage in the mass transfer experiments, only pure oxygen is used as the gas phase. A Taylor flow is generated in the channel (see Table 1) and it is allowed to stabilise for a short period of time. Then, a minimum of 5000 shadowgraphy and PLIF-I images are recorded successively using the corresponding illumination source and acquisition settings. This procedure is repeated for all the Taylor flow cases at the two $z$ locations.

Scattered light effect due to reflections at the bubble interface was modelled and removed from the oxygen concentration fields through specific experiments and an important image postprocessing step. This procedure is explained in detail in Butler 
Table 1

Parameters for description of two-phase flow hydrodynamics and mass transfer.

\begin{tabular}{|c|c|c|c|c|c|c|c|c|c|c|c|}
\hline Regime & $U_{\mathrm{b}}, \mathrm{m} / \mathrm{s}$ & $U_{\mathrm{tp}}, \mathrm{m} / \mathrm{s}$ & $L_{\mathrm{s}}, \mathrm{mm}$ & $L_{\mathrm{UC}}, \mathrm{mm}$ & $L_{\mathrm{b}}, \mathrm{mm}$ & $A, 1 / \mathrm{m}$ & $k_{\mathrm{L}} a, 1 / \mathrm{s}$ & $f_{\text {cir }}, \mathrm{Hz}$ & $D \cdot 10^{9}, \mathrm{~m}^{2} / \mathrm{s}$ & $t_{\text {film-slug, }} \mathrm{s}$ & $t_{\text {film-bubble, }} \mathrm{s}$ \\
\hline 1 & 0.0416 & 0.0412 & 6.70 & 16.4 & 9.70 & 766.5 & 0.06 & 1.5 & 2.00 & 0.235 & 0.162 \\
\hline 2 & 0.0923 & 0.086 & 7.10 & 17.0 & 9.90 & 749.2 & 0.08 & 2.8 & 2.00 & 0.117 & 0.075 \\
\hline 3 & 0.1402 & 0.124 & 9.30 & 15.8 & 6.50 & 516.6 & 0.13 & 2.9 & 1.99 & 0.099 & 0.025 \\
\hline 4 & 0.21 & 0.186 & 5.70 & 12.6 & 6.90 & 681.3 & 0.44 & 7.1 & 1.99 & 0.046 & 0.019 \\
\hline 5 & 0.274 & 0.233 & 6.00 & 11.1 & 5.10 & 548.8 & 0.46 & 8.0 & 1.98 & 0.038 & 0.008 \\
\hline 6 & 0.338 & 0.295 & 2.78 & 9.60 & 6.82 & 880.4 & 1.3 & 22.7 & 1.98 & 0.019 & 0.012 \\
\hline 7 & 0.393 & 0.34 & 2.20 & 9.70 & 7.50 & 908.8 & 1.89 & 32.6 & 1.98 & 0.015 & 0.012 \\
\hline 8 & 0.501 & 0.415 & 2.20 & 10.1 & 7.90 & 922.4 & 2.46 & 37.4 & 1.97 & 0.012 & 0.102 \\
\hline 9 & 0.283 & 0.246 & 6.40 & 12.8 & 6.37 & 594.6 & 0.31 & 8.2 & 1.97 & 0.038 & 0.012 \\
\hline 10 & 0.24 & 0.217 & 6.40 & 10.2 & 3.80 & 444.5 & 0.26 & 7.6 & 1.97 & 0.043 & 0.004 \\
\hline 11 & 0.097 & 0.081 & 6.70 & 15.3 & 8.60 & 692.9 & 0.13 & 2.4 & 1.70 & 0.118 & 0.058 \\
\hline 12 & 0.373 & 0.275 & 2.50 & 8.66 & 6.16 & 813.9 & 0.62 & 17.7 & 1.70 & 0.019 & 0.009 \\
\hline 13 & 0.097 & 0.078 & 6.40 & 14.3 & 7.90 & 664.7 & 0.11 & 2.3 & 1.31 & 0.118 & 0.052 \\
\hline 14 & 0.381 & 0.276 & 2.64 & 8.60 & 5.96 & 780.9 & 0.43 & 16.2 & 1.31 & 0.019 & 0.009 \\
\hline
\end{tabular}

et al. (2018). After the image analysis, the dissolved oxygen concentration is calculated with an uncertainty value of $\pm 5 \%$.

\section{Theoretical analysis of oxygen concentration fields in gas-liquid Taylor flow}

In this section a theoretical basis is presented, allowing for the analysis of mass transfer phenomena and evolution of concentration fields of the transferred substance in gas-liquid Taylor flow.

\subsection{Origin and characteristics of mass transfer intensification in the slug}

As stated in Section 1, it is widely stated in literature that the main reason for mass transfer (Abiev and Lavretsov, 2012) as well as heat transfer (Zhang et al., 2016; Leung et al., 2012) enhancement in two-phase Taylor flow is related to the Taylor vortices.

Indeed, the Taylor vortices (schematically represented in Fig. 1) allow for the performance of fast radial mass and heat transfer, even in a laminar flow, while for single-phase laminar flows the layers usually move in parallel without lateral mixing and any possible transport of matter in radial direction could only be performed by means of molecular diffusion. In Taylor flow however, radial transport is made possible within liquid slug by means of radial convection, as shown on Fig. 1.

Let us consider a water-air Taylor flow in a millichannel with $2 R=3 \mathrm{~mm}$, bubble velocity $U_{\mathrm{b}}=0.393 \mathrm{~m} / \mathrm{s}$, two-phase superficial velocity $U_{\mathrm{tp}}=0.34 \mathrm{~m} / \mathrm{s}$, and slug length $L_{\mathrm{s}}=2.2 \mathrm{~mm}$ (experimental data extracted from Butler et al. (2018)). It can be estimated that the circulation velocity is $w_{z}=0.1435 \mathrm{~m} / \mathrm{s}$ (Abiev, 2013). Considering that the radial velocity in Taylor vortex has the same order of magnitude according to the continuity equation, it comes $w_{r} \approx w_{z}=0.1435 \mathrm{~m} / \mathrm{s}$. As oxygen diffusivity in water is $D=2 \times$ $10^{-9} \mathrm{~m}^{2} / \mathrm{s}$, radial and axial Peclet numbers can be estimated:

$P e_{\mathrm{r}}=w_{\mathrm{r}} R / D=1.09 \times 10^{5}$, and $P e_{\mathrm{z}}=w_{\mathrm{r}} L_{\mathrm{s}} / D=1.59 \times 10^{5}$.

These two values confirm the significant predominance of convectional mass transfer mechanism in two-phase Taylor flow.

\subsection{Concentration distribution along the axial coordinate in plug or slug flow}

As often stated, the existence of series of well-mixed slugs present in a Taylor flow allows to consider the average liquid phase flow as plug flow in terms of concentration transport. This approach means that for the arbitrary fixed finite volume $d V$ having axial coordinate $z$, the mass balance of the oxygen dissolved in the liquid can be described by equation:

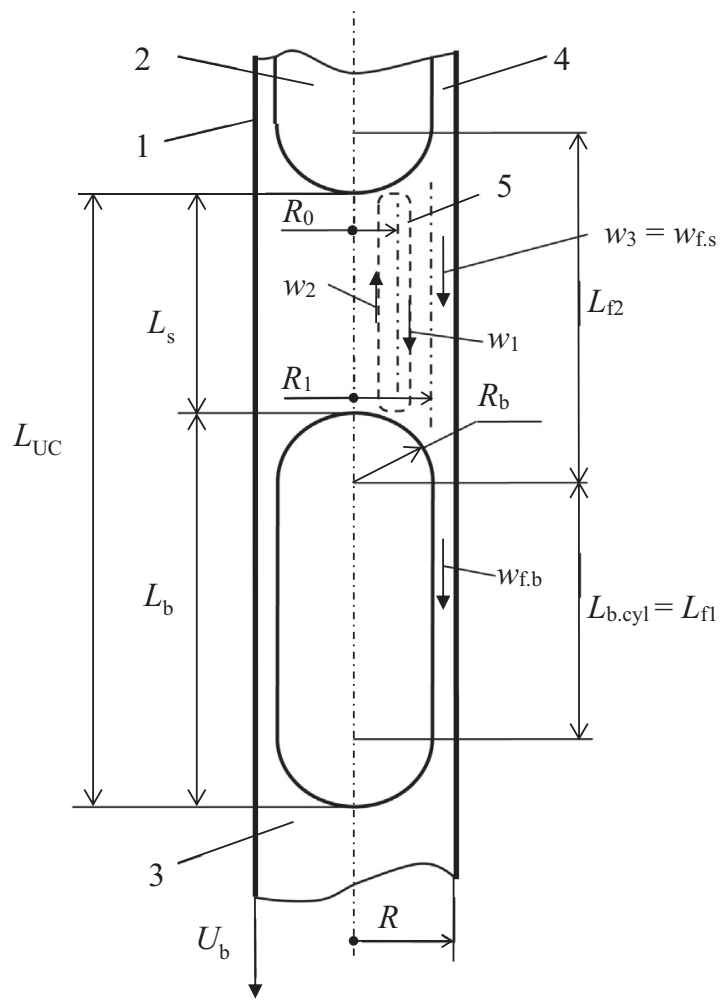

Fig. 1. Schematic of axial and radial convection by means of Taylor vortices in the liquid slug for liquid-gas two-phase flow in a milli-channel. 1 - capillary wall; 2 elongated bubble; 3 - liquid slug; 4 - liquid film around the bubble; 5 - circulation path in the Taylor vortex.

$\left(1-\varepsilon_{V}\right) d V \frac{\partial C(z)}{\partial t}=\left(q_{\text {in }}-q_{\text {out }}\right) A+k_{L} a\left[C^{*}-C(z)\right] d V$

where volumetric mass transfer coefficient $k_{L} a$ is attributed to the interfacial area contained in the finite channel differential volume $d V$.

Taking into account the definition of convective mass flux:

$q_{\text {in }}=U_{L} C(z), \quad q_{\text {out }}=U_{L}[C(z)+d C(z)]$,

and as $d V=A d z$, for steady state conditions one gets:

$\frac{d C(z)}{d z}=\frac{k_{L} a}{U_{L}}\left[C^{*}-C(z)\right]$

By assuming that the boundary condition for gas input into channel is $C(z=0)=0$, it is easy to find:

$C(z)=C^{*}\left[1-\exp \left(-\frac{k_{L} a}{U_{L}} z\right)\right]$ 
As conventionally done in literature, this equation is further used here for interpretation of experimental results and for building up a theoretical approach for the overall mass transfer in the milli channel. However, to relate the mass transfer coefficient in a more direct way to hydrodynamic phenomena, a slightly different definition is used in this work:

$\left(k_{L} a\right)_{U_{b}}=\left(k_{L} a\right) \frac{U_{b}}{U_{L}}$

Note that $\left(k_{L} a\right)_{U_{b}}$ and $\left(k_{L} a\right)$ follow identical trends. In the following, $\left(k_{L} a\right)_{U_{b}}$ is denoted as $\left(k_{L} a\right)$ in order to simplify the notations, and the values are directly taken from Butler et al. (2018).

\subsection{Definitions of circulation frequency and number of circulation cycles in the slug}

In Abiev (2013) some equations of the three-layer theory allowing to calculate time and spatial characteristics of two-phase Taylor flow are presented. In the following, the authors consider applying the schematic representation elaborated in Abiev (2013) to the experimental data obtained in Butler et al. $(2016,2018)$ in order to assess the three-layer approach.

The schematic of the unit cell including one bubble and one liquid slug in the frame of moving bubble is presented in Fig. 1.

It was shown in Abiev (2013) and in Butler et al. (2018) that the circulation time characteristics should play an important role in mass transfer intensification. Indeed, from a general point of view, the frequency of circulations $f_{\text {cir }}$ reflects the amount of elementary mass transfer events per unit of time. In that sense, the higher the frequency of circulations, the larger the transferred amount of substance. Of course, taking into account the complexity of mass transfer in twophase Taylor flow in millichannels, some other phenomena have to be considered which have a significant impact on the overall mass transfer, as mass exchanges from the film into the bulk slug. The simplified geometry of two-phase flow presented in Fig. 1 is then considered: the elongated bubble has a body of cylindrical shape with length $L_{\mathrm{b} . c y l}$, and hemispherical caps (nose and tail) with radius $R_{\mathrm{b}}$. The bubble is surrounded by liquid film with thickness $\delta$, and liquid slugs between bubbles have length $L_{s}$. According to the three-layer approach (Abiev, 2013), the velocity $w_{z}$ in the inner cylindrical layer with radius $R_{0}$ is equal to the velocity $w_{1}$ in the outer annular layer with radiuses $R_{1}$ and $R_{0}$ (see Abiev (2013) for details). Note that velocities $w_{1}$ and $w_{2}$ are relative values, i.e. they are defined in the frame of the moving bubble and equal to: $w_{1}=w_{2}=U_{t p}-\frac{1}{2} U_{b}$.

In these assumptions and considering (i) that the Poiseuille profile - widely proven in literature and observed in Butler et al. (2018) - exists across channel section in a wide part of the slug, and (ii) that $\left(R_{1}-R_{0}\right)$ is negligible in regard with $L_{\mathrm{s}}$, then the frequency of circulations could be defined as:

$f_{\text {cir }}=\frac{w_{2}}{2 L_{s}+2\left(R_{1}-R_{0}\right)} \approx \frac{w_{2}}{2 L_{s}}=\frac{U_{t p}-U_{b} / 2}{2 L_{s}}$

The period of circulations is defined as:

$T_{\text {cir }}=\frac{1}{f_{\text {cir }}}$

Note that this calculation of $T_{\text {cir }}$ is also explained in Butler et al (2018) based on the expressions previously given in Thulasidas et al. (1997). In Butler et al. (2018), this parameter corresponds to half-way of circulation loop $L_{s}$. In the present manuscript it corresponds to the whole length of circulation loop $2 L_{\mathrm{s}}$, and is thus a time period reciprocal to the frequency of circulations which is more convenient to use here.

The residence time of the slug in the capillary with the length of $L_{\mathrm{c}}$ is:
$T_{\text {res }}=\frac{L_{c}}{U_{t p}}$

The number of circulations during residence time is:

$N_{c i r}=\frac{T_{r e s}}{T_{c i r}}=f_{c i r} T_{r e s}=\frac{U_{t p}-U_{b} / 2}{2 U_{t p}} \frac{L_{c}}{L_{s}}$

Some ratios are then introduced, such as:

$\eta=\frac{U_{b}}{U_{t p}}$

$\frac{L_{c}}{L_{s}}=\frac{L_{c}}{L_{U C}} \frac{L_{U C}}{L_{s}}=N_{U C} \frac{L_{U C}}{L_{s}}$

Here $N_{\mathrm{UC}}$ is the number of unit cells along the channel, one can thus derive:

$N_{c i r}=\left(1-\frac{\eta}{2}\right) \frac{L_{c}}{2 L_{U C}} \frac{L_{U C}}{L_{S}}=\left(1-\frac{\eta}{2}\right) \frac{N_{U C}}{2\left(1-\varepsilon_{L}\right)}$

where $\varepsilon_{\mathrm{L}}$ is the ratio of the bubble length to the length of the unit cell, $\varepsilon_{\mathrm{L}}=L_{\mathrm{b}} / L_{\mathrm{UC}}$ (more exact definition was used in Abiev (2010) where the equivalent length of the bubble was used), then $1-\varepsilon_{\mathrm{L}}=$ $L_{\mathrm{S}} / L_{\mathrm{Uc}}$. Note that in general the actual gas holdup $\varepsilon_{\mathrm{V}}$ verifies $\varepsilon_{\mathrm{V}}<\varepsilon_{\mathrm{L}}$.

Physical analysis of Eq. (12) seems robust: with growing $N_{U C}$ (i.e. with decreasing length of the unit cells $L_{U C}$ ) and raising $\varepsilon_{\mathrm{L}}$ (i.e. with increasing length of the bubbles $L_{\mathrm{b}}$ and decreasing length of the slugs $L_{S}$ for given $L_{U C}$ value), the number of circulations in the liquid slug $N_{\text {cir }}$ rises.

The second conclusion from Eq. (12) is that with growing $\eta$ (the limit for Taylor circulations is $\eta=2$ ) no circulation takes place at all (Taylor, 1961). The growth of $\eta$ value occurs with increase of Ca number, and when it approaches approximately to critical value $\mathrm{Ca}^{*}=0.7$ (the latter in fact depends on the angle between twophase flow in the channel and the gravitational acceleration, see Abiev, 2009 for details), $\eta$ approaches to 2 .

In Section 3.2 the axial distribution of dissolved oxygen concentration along the channel was derived (Eq. (4)) on the basis of onedimensional model. Let us consider one cycle of Taylor circulation in the liquid slug. The distance travelled by the slug during one period of circulation $T_{\text {cir }}$ (one cycle) is assessed as:

$L_{\text {cycle }}=U_{t p} T_{\text {cir }}=\frac{U_{t p}}{f_{\text {cir }}}$

Putting Eq. (13) into Eq. (4) leads to the concentration of oxygen dissolved in liquid after one cycle of circulation:

$C z=L_{\text {cycle }}=C^{*}\left[1-\exp \left(-\frac{k_{L} a}{f_{\text {cir }}}\right)\right]$

Similarly, for the estimation of the concentration of dissolved oxygen in liquid at the end of channel with length $L_{c}$, it is easy to derive from Eqs. (8) and (9):

$L_{c}=\frac{U_{t p}}{f_{\text {cir }}} N$

Then, at the outlet of the channel:

$C\left(z=L_{c}\right)=C^{*}\left[1-\exp \left(-\frac{k_{L} a}{f_{\text {cir }}} N_{c i r}\right)\right]$

3.4. Relation between mass transfer characteristics and circulation frequency

Analysis of the experimental data published in Butler et al. (2016, 2018) (see Fig. 2(a)) reveals a linear dependence between $k_{\mathrm{L}} a$ and $f_{\text {cir }}$ (Eq. (17)) for most studied regimes, with high determination coefficient. 

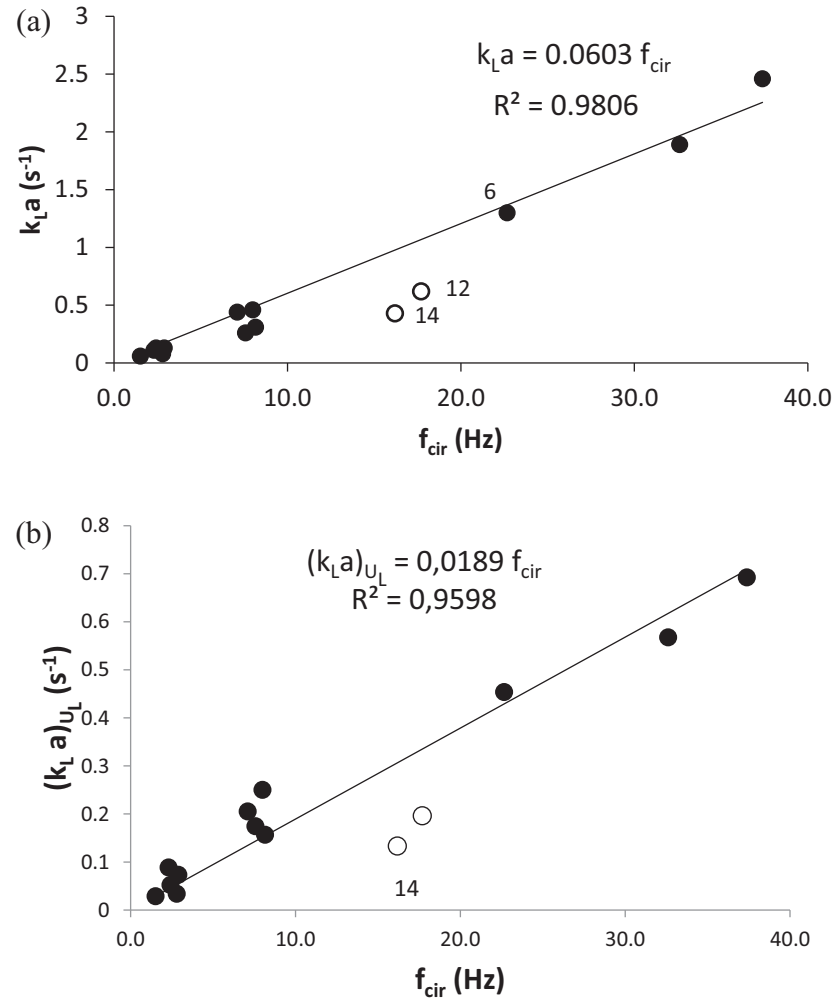

Fig. 2. Correlations of experimental values of (a) $k_{\mathrm{L}} a$ (based on $U_{b}$ ) and (b) $\left(k_{L} a\right)_{U_{L}}$ on circulation frequency $f_{\text {cir. }}$. Trend lines are built by use of dark marks (all regimes except 12 and 14). The Reynolds number based on the bubble velocity lies between 70 and 1400, the Schmidt number is always greater than 500 .

$k_{\mathrm{L}} a=0.0603 f_{\text {cir }}$,

Except for regimes (12) and (14) and for regimes corresponding to $k_{\mathrm{L}} a$ values close to 0 , Eq. (17) describes data within $12 \%$ error. Regimes (12) and (14) show the most significant deviation from Eq. (17). This point will be discussed in the next section. Note that these tendencies apply only if the bubbles and slugs are flowing (i.e. $f_{\text {cir }} \neq 0$ ), and stand for mass transfer at high Schmidt number ( $>500$ in all the investigated cases).

In Butler et al., 2018, thanks to the concentration fields of dissolved oxygen obtained in two positions along the capillary, the contributions from the film and the bubble caps were highlighted: it has been shown that, because the concentration in the film region (all along the tube) is always higher than the average slug concentration, the film region contributes to supply the slug in oxygen by diffusion across the dividing streamline separating these two regions, additionally to the fluxes transferring from the bubble caps to the slug. Despite this complex dynamics, the present linear relation Eq. (17) proves that the recirculation motion inside the slug drives the mass transfer and is sufficient to predict accurately the overall transfer rate. Then, Eq. (17), showing that $\frac{k_{L} a}{f_{c i r}} \approx$ Constant $=\alpha$, provides a simple correlation to predict the $k_{\mathrm{L}} a$ value and to understand the influence of the operating parameters on the mass transfer rate. Note that the fraction $\alpha$ reflects the rate of concentration rise during one single cycle. By interpreting Eq. (16) in the following way:

$C\left(z=L_{c}\right)=C^{*}\left[1-\exp \left(-\alpha N_{c i r}\right)\right]$

Eq. (18) shows that the number of circulations $N_{\text {cir }}$ could also serve as a sole parameter characterizing the rate of oxygen concentration dissolved in the liquid for a residence time $T_{\text {res }}$ along the channel of length $L_{\mathrm{c}}$, instead of the $k_{\mathrm{L}} a$ value but in an equivalent way since
$k_{L} a T_{r e s}=\frac{k_{L} a}{U_{t p}} L_{c}=\frac{k_{L} a}{f_{c i r}} N_{c i r}=\alpha N_{c i r}$

Based on Fig. 2(b), note that the relationship between the volumetric mass transfer coefficient and the circulation frequency is still valid (with a different slope) when the $k_{L} a$ based on $U_{L}$, $\left(k_{L} a\right)_{U_{L}}$, is defined, according to the Eq. (20):

$\left(k_{L} a\right)_{U_{L}}=\left(k_{L} a\right)_{U_{b}} \frac{U_{L}}{U_{b}}$

Points from regimes 12 and 14 presents again a deviation from the general trend, in a similar way than in Fig. 2(a), showing that the interpretation of the parameters influencing the mass transfer rate is the same whatever the definition of the mass transfer coefficient.

The volumetric mass transfer coefficient $k_{L}$ agives the characteristic frequency of the transfer process and is commonly employed. However, a measure of the intrinsic characteristic of mass transfer intensity in a multiphase system is better given by the $k_{\mathrm{L}}$ mass transfer coefficient. As for $k_{\mathrm{L}} a$, it is observed here that mass transfer coefficient shows an almost linear function of circulation frequency: $k_{\mathrm{L}}=f_{2}\left(f_{\text {cir }}\right)$ for almost all investigated cases (see Fig. 3 ).

Finally, we found here that both functions $k_{\mathrm{L}} a=f_{1}\left(f_{\text {cir }}\right)$ and $k_{\mathrm{L}}=$ $f_{2}\left(f_{\text {cir }}\right)$ are quasi-linear. This is explained by the fact that the interfacial area $a=f_{3}\left(f_{\text {cir }}\right)$ for the 14 considered cases varies much less than the $k_{\mathrm{L}}=f_{2}\left(f_{\text {cir }}\right)$ function. Indeed, the span range of $k_{\mathrm{L}}$ is from $0.08 \cdot 10^{-3} \mathrm{~m} / \mathrm{s}$ to $2.7 \cdot 10^{-3} \mathrm{~m} / \mathrm{s}$, i.e. 34 times from the lowest value to the highest one. The span of $a$ in the performed study is from 440 to $9201 / \mathrm{m}$, i.e. 2.09 times between highest and lowest values (see Fig. 4).

It is surprising to observe here such a weak variation of $a$. Let us discuss this parameter which is of primary importance for mass transfer. Going back to Fig. 1, the cylindrical body of the bubble has length $L_{\mathrm{b} \text {.cyl }}=L_{\mathrm{f} 1}$, where $L_{\mathrm{f} 1}=L_{\mathrm{b}}-2 R_{\mathrm{b}}$. Slug length is $L_{\mathrm{s}}$. The specific interfacial area in one unit cell volume can then be derived:

$a=\frac{S_{b}}{V_{U C}}=\frac{2 \pi R_{b} L_{f 1}+4 \pi R_{b}^{2}}{\pi R^{2}\left(L_{b}+L_{s}\right)}$,

leading to:

$a=\frac{2 R_{b}\left(L_{b}-2 R_{b}\right)+4 R_{b}^{2}}{R^{2}\left(L_{b}+L_{s}\right)}=\frac{2 R_{b} L_{b}}{R^{2}\left(L_{b}+L_{s}\right)}=\frac{2 R_{b}}{R^{2}\left(1+\frac{L_{s}}{L_{b}}\right)}$

It is clear that specific interfacial area usually depends on the geometrical properties of the channel $\left(R_{\mathrm{b}}\right.$, which is linked with $R$

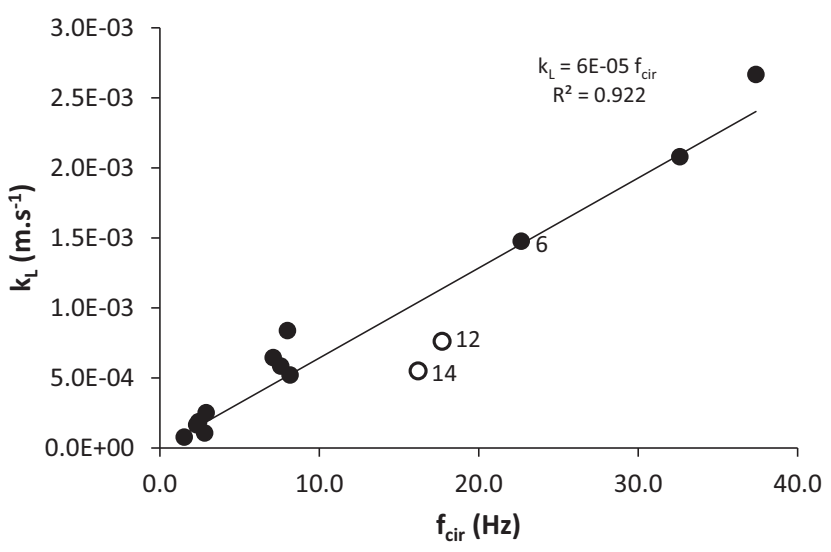

Fig. 3. Correlation of experimental values of $k_{\mathrm{L}}$ on circulation frequency $f_{\text {cir }}$, as based on experimental data from Butler et al. (2018). Trend lines are built by use of all experimental regimes except 12 and 14. 


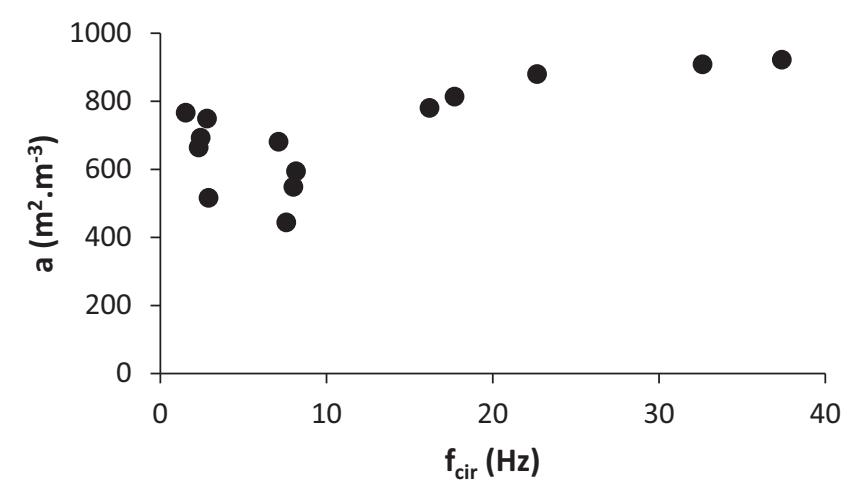

Fig. 4. Dependence of specific interfacial area in unit cell on frequency of circulations $f_{\text {cir }}$ (experimental values from Butler et al. (2018)).

and with Ca number) and on the characteristic dimensions of continuous and dispersed phases, $L_{\mathrm{b}}$ and $L_{\mathrm{s}}$. As $L_{\mathrm{b}}$ usually grows with increasing $U_{\mathrm{G}} / U_{t p}$ and drops with increasing $U_{\mathrm{L}} / U_{t p}$, not only geometrical but also hydrodynamics parameter have influence on the specific interfacial area. For the studied range of parameters, $U_{\mathrm{G}} / U_{t p}$ varies from 0.36 to 0.66 only (and $U_{\mathrm{L}} / U_{t p}$ from 0.44 to 0.77 only), leading to a narrow variation of the specific interfacial area as compared to the $k_{\mathrm{L}}$ mass transfer coefficient variations. This is probably due to the specific experimental setup used in the work of Butler et al. (2016, 2018), and more precisely to the way that gas and liquid flows are segmented in their T-junction.

In future works, $U_{\mathrm{G}}$ and $U_{\mathrm{L}}$ will vary in wider ranges and special attention should be paid to the behavior of $a$ as a function of mixer geometry and $U_{\mathrm{G}}$ and $U_{\mathrm{L}}$ values.

\subsection{Discussion about the deviation from linear trend of two cases for mass transfer coefficients}

Cases 12 and 14 of Butler et al. (2018) do not match the linear trend for $k_{\mathrm{L}} a$ versus $f_{\text {cir }}$ (Fig. 2). This may be attributed to several physical reasons developed here.

Let us compare the flow parameters for regimes 12 and 14 from one side and those corresponding to regime 6 from the other side: regime 6 follows the linear trend for $k_{\mathrm{L}} a$ versus $f_{\text {cir }}$ (see Fig. 2); yet, its parameters $U_{\text {tp }}$ and $L_{\mathrm{s}}$ are similar to those for regimes 12 and 14 (emphasised in bold in Table 1). What is more, values of $f_{\text {cir }}$ are close for the 3 considered regimes: $17.7 \mathrm{~Hz}$ for regime 12 , $16.2 \mathrm{~Hz}$ for regime $14,22.7 \mathrm{~Hz}$ for regime 6 . However, the $k_{\mathrm{L}} a$ values for regimes 12 and 14 are approximately 1.5 or 2 times lower than those predicted by Eq. (17). This deviation may be explained by the following reasons:

(1) Large capillary number for regimes 12 and 14 of 0.030 and 0.067 , respectively, whereas $\mathrm{Ca}<7 \cdot 10^{-3}$ for most of the other regimes except regimes 11 and 13 (which were also performed with viscous liquid phase), implying large lubrication film $(210 \mu \mathrm{m}$ and $128 \mu \mathrm{m}$ respectively, while all other regimes show a film thickness lower than $90 \mu \mathrm{m}$ ): as a consequence, bubble tail and cap are smaller in regimes 12 and $14(10 \%$ and $20 \%$ difference in contact area with regards to regime 6 ), so the contact time between them and the liquid slug is shorter and the resulting amount of oxygen transferred is smaller.

(2) Thick film for regimes 12 and 14, leading to high film volume fraction in the unit cell $\left(V_{\mathrm{f}} / V_{\mathrm{s}}\right.$ reaches 0.5 for both regimes): since film volume presents a high resistance due to diffusion whereas its volume contribution is high, mass transfer dynamics is obviously very different than that of the other regimes.
(3) Shorter slug and higher two-phase velocity for regimes 12 and 14 as compared to the other thick-film regimes (regimes 11 and 13), leading to shorter contact times between (i) the film and the lateral side of the bubble $\left(t_{\text {film-slug, defined as }}\right.$ $\left(L_{s}+2 \cdot R_{b}\right) / U_{t p}$, is $\sim 0.02 \mathrm{~s}$ for regimes 12 and 14 whereas it is $\sim 0.2 \mathrm{~s}$ for regimes 11 and 13 ), and between (ii) the near-

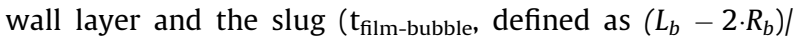
$U_{b}$, see values in Table 1$)$. Therefore, in regimes 12 and 14 , these thick films cannot significantly enrich in dissolved gas nor take significant part in mass transport to the slug, which reduces their contribution in the transfer process. Then, it is not surprising that the global rate of transfer is different than in cases where the circulating motion controls the transfer dynamics, with an active film contributing to the transfer by being a boundary of the circulating motion with a concentration close to saturation.

As a consequence, Taylor flows showing the same characteristics as those described above may not follow the linear dependence of $k_{\mathrm{L}} a$ as a function of $f_{\text {cir. }}$.

\subsection{On the emergence of 'concentrated islands' in the slug}

It was observed in Butler et al. (2018), in the various experimental fields of dissolved oxygen concentration in slugs, that some cases show unusual areas (here after called 'concentrated islands') of higher concentration emerging in the slugs. This is illustrated in Fig. 5 through pictures corresponding to regimes 1 and 11 , and 3 and 9.

It is recalled that, in the experimental work, gas and liquid phases were fed to the channel by means of a T-mixer. The following mechanism is proposed here in order to explain the emergence of these "concentrated islands". Fig. 6 shows how the "concentrated islands" may be created during bubble growth in the vicinity of the T-mixer. The process stages are described here under, in relation with the schemes drawn in Fig. 6.

(a) bubble grows and hinders liquid flow except for a thin area between bubble and channel wall. This flow enriches in dissolved oxygen when passing close to bubble interface.

(b) upstream from the bubble, the streamlines of the flow are directed towards channel center: they transport dissolved oxygen in that direction.

(c) when bubble detaches, a significant amount of liquid rich in dissolved gas lays between the two neighbor bubbles. When circulation starts between them, this enriched liquid amount is split and enclosed in the center of the Taylor vortices, creating the 'concentrated islands'. During slug's travel along the channel (in the work described in Butler et al. (2018), the measuring point is situated $40 \mathrm{~cm}$ away from T-mixer), the islands stay locked in the center of the circulating streamlines of the slug, where hardly no convective motion exists (in bubble frame reference).

The 'concentrated islands' would probably not appear in following cases:

- If the velocity is small, kinetic energy of the flow is too low to detach the rich film from the bubbles surface: for regimes 1 , 2, 11-14 in Butler et al. (2018), the Reynolds number is: $\operatorname{Re}_{1}=118, \operatorname{Re}_{2}=263, \operatorname{Re}_{11-14}=32-268$. This is in perfect agreement with the critical Reynolds number claimed in Butler et al. (2018).

- If slug length is short, the Taylor vortices build up earlier, the 'concentrated island' is curved, as can be seen for regimes 6-8 in (Butler et al., 2018). 
(a)

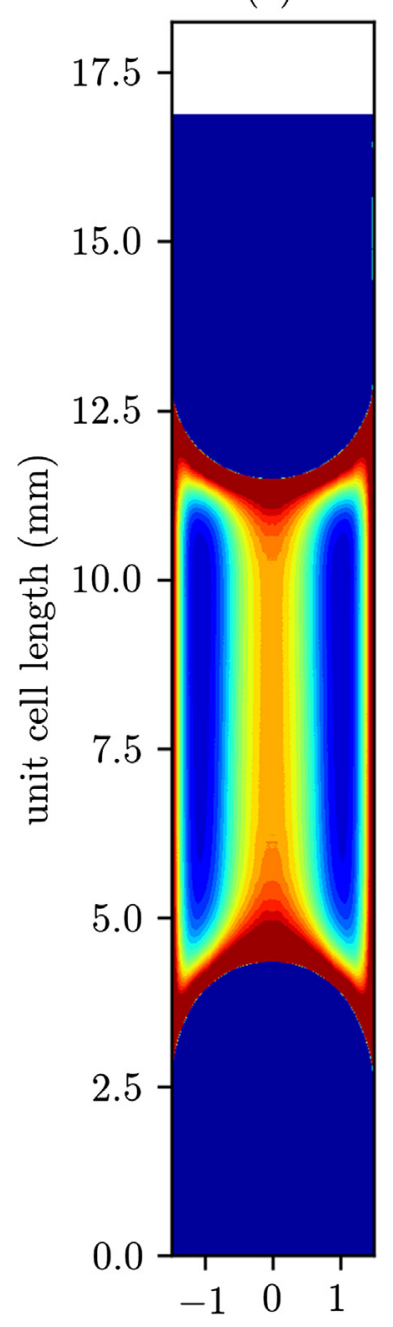

(b)

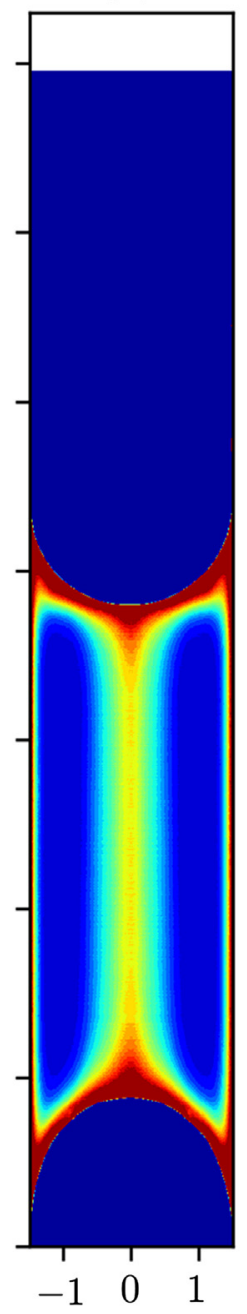

(c)
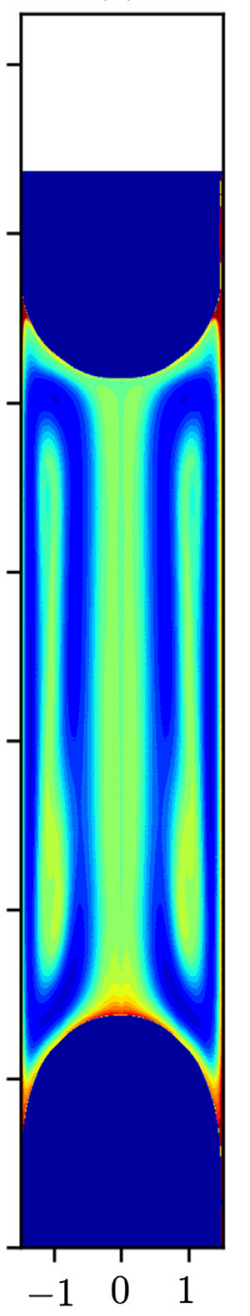

(d)

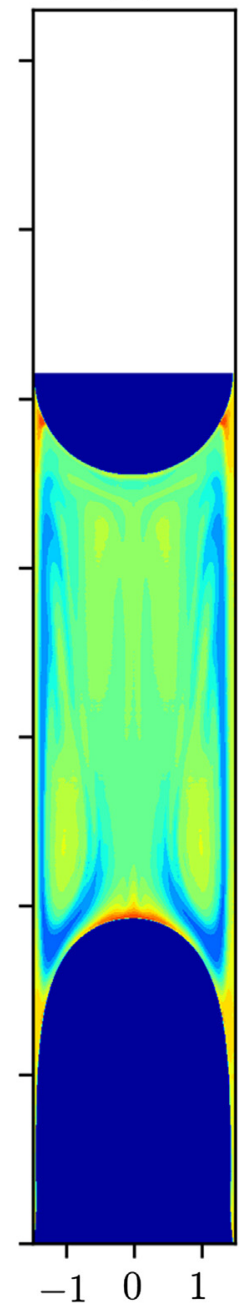

unit cell width $(\mathrm{mm})$

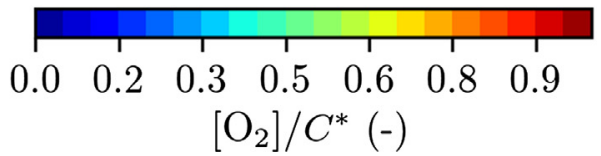

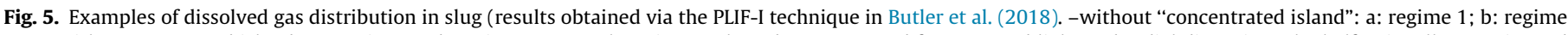

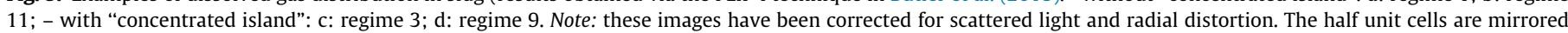
about the axial centreline. The $\left[\mathrm{O}_{2}\right]$ values inside the bubble have been set to 0 for clarity.

Despite of the presence of these "concentrated islands", note that all the cases where they are observed still follow the linear relation between $k_{\mathrm{L}} a$ and $f_{\text {cir }}$ (Eq. (17)).

\section{Conclusions}

The results obtained in Butler et al. (2016, 2018) were analyzed in this work from different points of view. Taylor flow is complex and some specific parameters of flow have been taken into account via physical modeling of mass transfer in two-phase Taylor flow. In particular, the three-layer approach (Abiev, 2013) allowed a convenient representation of Taylor flow in order to analyze the experimental results obtained in Butler et al. $(2016,2018)$.
The relation between the circulation in slugs and the $k_{\mathrm{L}} a$ value was quantified. The use in Butler et al. (2018) of liquid phase of different properties (water, and Breox-water solutions with viscosity of 4.2 and $9.2 \mathrm{mPa} \mathrm{s}$ ) conveniently allowed various magnitudes of circulation velocity and lubrication film thickness, staying at large Reynolds number (between 70 and 1400), large Schmidt number (superior to 500) and low capillary number (less than 0.067). In some cases, film thickness around bubbles and slugs was much higher than for pure water, resulting in poorly saturated film and leading to a dramatic decrease of $k_{\mathrm{L}} a$ for high capillary numbers. However, the experimental regimes obtained with the water-air system emphasize the role of the circulation frequency and of the number of circulation cycles in the slug for mass transfer intensity. Considering the periodical contacts between bubble and slug 


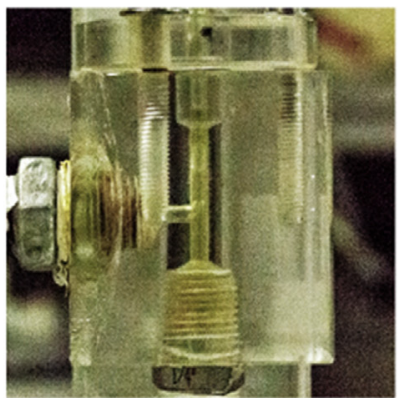

(a)

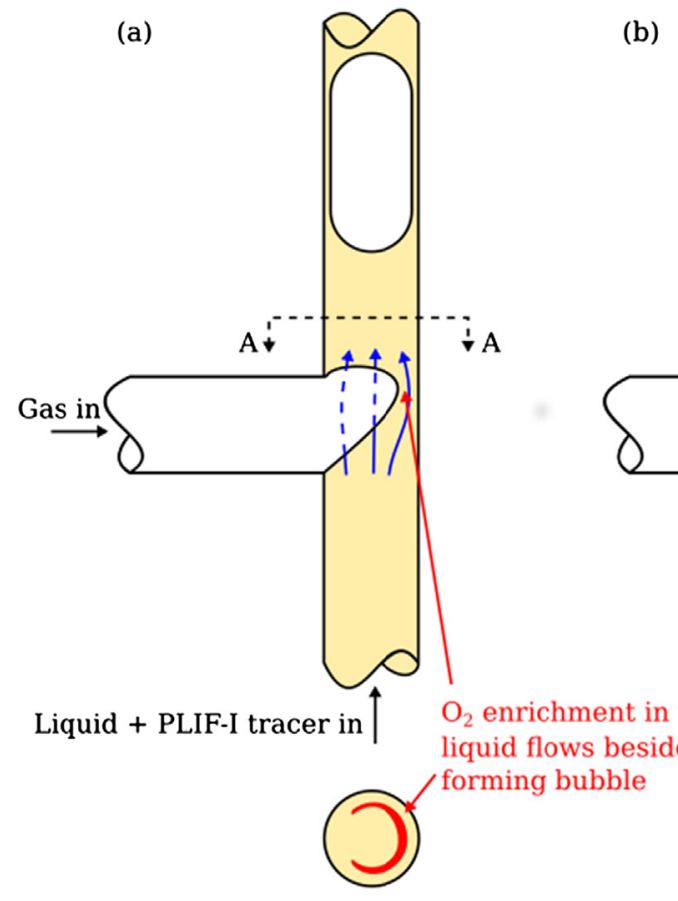

SECTION A-A (b)

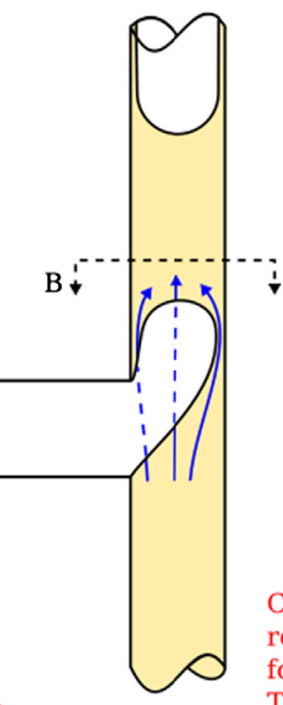

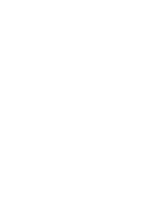

(c) B

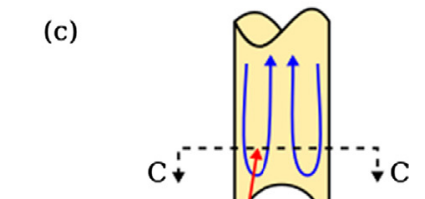

Concentrated island ring remains trapped after formation of bubble and Taylor vortex<smiles>c1ccccc1</smiles>

SECTION B-B

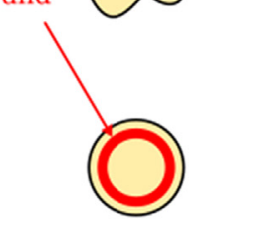

SECTION C-C

Fig. 6. Schematic representation of the emergence of 'concentrated islands' in the slug; role of unsymmetrical gas input through T-mixer.

(during Taylor circulations), and between bubble and film, it is logical to expect that the temporal coordinate could be replaced by $N_{\text {cir }} / f_{\text {cir. }}$ In such cases, a univocal linear relation was found between $k_{\mathrm{L}} a$ and circulation frequency in slugs. This relation (Eq. (17)) is observed to be valid for all experimental cases where the mass transfer diffusional steps in the lubrication film are not limiting for the overall mass transfer rate. Then, even though the film is rapidly saturated and becomes an additional source of oxygen that contributes to supply the slug, the global rate of transfer is mainly determined by the intensity of internal circulation in the slug.

Experimental data of oxygen concentration in slug flow in millichannels obtained by PLIF-I technique in Butler et al. (2018) also surprisingly revealed, under some experimental conditions, the existence within the slug of 'concentrated islands' of higher concentration. A mechanism was described to explain their emergence, and the conditions to allow their existence have been discussed. Though this phenomenon needs further investigation to be fully understood, it could be assumed that the combined actions of bubble formation in a non-symmetrical gas injection device and liquid flow inertia play a major role in this effect.

The disposal of high spatial resolution experimental data, as available in Butler et al. (2018), has allowed new insight into gas liquid flows and gas liquid mass transfer mechanisms. Note that the relation Eq. (17) for mass transfer rate prediction, shown here to be valid with data obtained in a milli-channel, can be expected to be also applicable in micro-channels where the flow hydrody- namics is the same. However, the theoretical items stated in this paper need extended set of experimental or numerical data to further prove all influencing factors.

\section{Declaration of Competing Interest}

The work was partially financially supported by the Russian Foundation for Basic Research according to the research project N2 18-03-00206-a. There are no other potential conflicts of interest.

\section{References}

Abiev, R.S., 2009. Circulation and bypass modes of the slug flow of a gas-liquid mixture in capillaries. Theor. Found. Chem. Eng. 43 (3), 298-306.

Abiev, R.S., 2010. Method for calculating the void fraction and relative length of bubbles under slug flow conditions in capillaries. Theor. Found. Chem. Eng. 44 (1), 86-101.

Abiev, R., 2013. Bubbles velocity, Taylor circulation rate and mass transfer model for slug flow in milli- and microchannels. Chem. Eng. J. 227, 66-79. https://doi.org/ 10.1016/j.cej.2012.10.009.

Abiev, R.S., Lavretsov, I.V., 2012. Intensification of mass transfer from liquid to capillary wall by Taylor vortices in minichannels, bubble velocity and pressure drop. Chem. Eng. Sci. 74, 59-68.

Bercic, G., Pintar, A., 1997. The role of gas bubbles and liquid slug lengths on mass transport in the Taylor flow through capillaries. Chem. Eng. Sci. 52, 3709-3719.

Butler, C., Cid, E., Billet, A.-M., 2016. Modelling of mass transfer in Taylor flow: investigation with the PLIF-I technique. Chem. Eng. Res. \& Des. 115, 292-302. https://doi.org/10.1016/j.cherd.2016.09.001.

Butler, C., Lalanne, B., Sandmann, K., Cid, E., Billet, A.-M., 2018. Mass transfer in Taylor flow: Transfer rate modelling from measurements at the slug and film 
scale. Int. J. Multiph. Flow 105, 185-201. https://doi.org/10.1016/j. ijmultiphaseflow.2018.04.005.

Dietrich, N., Loubière, K., Jimenez, M., Hébrard, G., Gourdon, C., 2013. A new direct technique for visualizing and measuring gas-liquid mass transfer around bubbles moving in a straight millimetric square channel. Chem. Eng. Sci. 100, 172-182. https://doi.org/10.1016/j.ces.2013.03.041.

Kováts, P., Pohl, D., Thévenin, D., Zähringer, K., 2018. Optical determination of oxygen mass transfer in a helically-coiled pipe compared to a straight horizontal tube. Chem. Eng. Sci. 190, 273-285. https://doi.org/10.1016/j. ces.2018.06.029.

Kreutzer, M.T., Du, P., Heiszwolf, J.J., Kapteijn, F., Moulijn, J.A., 2001. Mass transfer characteristics of three-phase monolith reactors. Chem. Eng. Sci. 56, 60156023.

Leung, S.S.Y., Gupta, R., Fletcher, D.F., Haynes, B.S., 2012. Effect of flow characteristics on Taylor flow heat transfer. Ind. Eng. Chem. Res. 51 (4), 2010-2020.

Matsuoka, A., Noishiki, K., Mae, K., 2016. Experimental study of the contribution of liquid film for liquid-liquid Taylor flow mass transfer in a microchannel. Chem. Eng. Sci. 155, 306-313.

Sattari-Najafabadi, M., Nasr Esfahany, M., 2017. Intensification of liquid-liquid mass transfer in a circular microchannel in the presence of sodium dodecyl sulfate. Chem. Eng. Proc.: Proc. Int. 117, 9-17. https://doi.org/10.1016/j.cep.2017.03.011.

Sattari-Najafabadi, M., Nasr Esfahany, M., Wu, Z., Sunden, B., 2018. Mass transfer between phases in microchannels: A review. Chem. Eng. Proc.: Proc. Intens. 127, 213-237. https://doi.org/10.1016/j.cep.2018.03.012.
Svetlov, S.D., Abiev, R.S., 2016. Modeling mass transfer in a Taylor flow regime through microchannels using a three-layer model. Theor. Found. Chem. Eng. 50 (6), 975-989. https://doi.org/10.1134/S0040579516060166.

Taylor, G.I., 1961. Deposition of a viscous fluid on the wall of a tube. J. Fluid Mech. $10,161-165$

Thulasidas, T.C., Abraham, M.A., Cerro, R.L., 1997. Flow patterns in liquid slugs during bubble-train flow inside capillaries. Chem. Eng. Sci. 52 (17), 2947-2962.

van Beaten, J.M., Krishna, R., 2004. CFD simulations of mass transfer from Taylor bubbles rising in circular capillaries. Chem. Eng. Sci. 59, 2535-2545. https://doi. org/10.1016/j.ces.2004.03.010.

Wang, K., Lur, G., 2017. Microflow extraction: A review of recent development. Chem. Eng. Sci. 169, 18-33. https://doi.org/10.1016/j.ces.2016.10.025.

Yang, L., Loubière, K., Dietrich, N., Le Men, C., Gourdon, C., Hébrard, G., 2017. Local investigations on the gas-liquid mass transfer around Taylor bubbles flowing in a meandering millimetric square channel Chem. Eng. Sci. 165, 192-203. https:// doi.org/10.1016/j.ces.2017.03.007.

Yule, J., Ludo, L., Gonthier, Y., Chen, G., Yuan, Q., 2009. An experimental study of airwater Taylor flow and mass transfer inside square microchannels. Chem. Eng. Sci. 64, 3697-3708.

Chang, J., Fletcher, D.F., Li, W., 2016. Heat transfer and pressure drop characteristics of gas-liquid Taylor flow in mini ducts of square and rectangular cross-sections. Int. J. Heat Mass Transf. 103, 45-56. 